\title{
Incidence of acute spinal cord injury and associated complications of methylprednisolone therapy: a national population-based study in South Korea
}

\author{
Sung Hoon Choi ${ }^{1} \cdot$ Chang-ho Sung ${ }^{1} \cdot$ Dong Ryul Heo ${ }^{1} \cdot$ Soo-Young Jeong $\mathbb{( I )}^{1} \cdot$ Chang-Nam Kang $^{1}$
}

Received: 17 June 2019 / Revised: 25 August 2019 / Accepted: 31 August 2019 / Published online: 16 September 2019

(c) The Author(s), under exclusive licence to International Spinal Cord Society 2019

\begin{abstract}
Study design Retrospective population-based cohort study

Objectives To evaluate the incidence of acute spinal cord injury (SCI) in South Korea, and the prescription rates and complications related to high dose methylprednisolone therapy.

Setting Health Insurance Review and Assessment Service (HIRA) data

Methods National database of the Korean HIRA between 2007 and 2017 was reviewed. To identify patients with acute SCI and the use of high dose methylprednisolone, International Classification of Disease revision codes, medical behavior codes and examination codes were used. Patients were grouped according to whether or not they received methylprednisolone therapy (MP group vs non-MP group).

Results The average age-adjusted incidence of acute SCI per 1,000,000 persons was 26.4 and the peak incidence was in the 50s overall. The methylprednisolone prescription rate was highest in $2012(76 \%)$ and continued to decrease thereafter, being lowest in 2017 (41\%). The MP group showed higher complication rates in terms of pneumonia (OR 1.8, 95\% CI, 1.62-2.0), GI bleeding (OR 1.2, 95\% CI, 1.05-1.38), and UTI (OR 1.68, 95\% CI, 1.53-1.84). The average length of hospitalization was longer in patients who received methylprednisolone (26.5 days vs. 24.4 days, $p<0.05$ ).

Conclusions The average age-adjusted incidence of acute SCI for 11 years was 26.4 per 1,000,000 persons and highest in 50s. Strategies should be established, and national health resources should be allocated to prevent acute SCI from occurring in older people. The prescription rate of high dose methylprednisolone for acute SCI is decreasing in South Korea but it is still high.
\end{abstract}

\section{Introduction}

Acute spinal cord injury (SCI) is a catastrophic traumatic event that affects the physical and psychological wellbeing of individuals, and results in considerable socio-economic losses $[1,2]$. The high treatment costs and extended hospitalization have a tremendous impact on the individual and their family and are a substantial financial burden on the

Supplementary information The online version of this article (https:// doi.org/10.1038/s41393-019-0357-2) contains supplementary material, which is available to authorized users.

Chang-Nam Kang

cnkang65@hanyang.ac.kr

1 Department of Orthopaedic Surgery, Hanyang University College of Medicine, Seoul, Republic of Korea health care system. Therefore, identifying the epidemiology of acute SCI is essential for health care providers to establish policies for preventing the disease and redistributing resources.

Several studies have compared the prevalence and incidence rates of acute SCI in different geographical and economic conditions [3, 4]. In particular, the reported incidence rates of acute SCI differ widely according to research method, date, and region; in developed nations, it has been reported variously as $11.5-53.4$ persons per million persons [5, 6] and 13.0-220.0 persons per million in developing countries [7, 8]. Acute SCI patients have been reported to account for $2.6 \%$ of the patients in major trauma centers in North America [5], and not only are there more than 10,000 new patients every year, but this number would be much higher if individuals who expire before arriving at the hospital were included $[6,9,10]$. However, most data on acute SCI are based on developed nations such as the US 
and Spain, and data for developing nations such as Africa, South America and Asia are limited [11].

After the report on the effect of high dose methylprednisolone treatment for acute SCI by Bracken et al. [12], a number of studies were conducted to examine the efficacy of methylprednisolone [13, 14]. According to recent studies, the use of methylprednisolone for acute SCI patients leads to increased numbers of complications, without having any beneficial effect on neurological symptoms, and therefore, methylprednisolone is not recommended as first line treatment $[15,16]$. Although the Food and Drug Administration (FDA) no longer recommends methylprednisolone for treating acute SCI $[15,16]$, many countries including South Korea still use it [17].

Therefore, in this study we assessed the incidence of acute SCI in South Korea and investigated the prescription rate of methylprednisolone for acute SCI over the years, and the acute complications following its use in a populationbased study using a national database.

\section{Methods}

\section{Data source and study population}

This was a retrospective population-based cohort study using the database of the Health Insurance Review and Assessment Service (HIRA). Korea's national health insurance system, which began in 1989, is operated by the government and covers medical expenses for outpatient, inpatient, and emergency medical services. Apart from cosmetic services such as plastic surgery, almost all medical services are covered by the system. All citizens are required to subscribe to it, and it covers over $98 \%$ of the Korean population, working with all hospitals and clinics. As a result, the system boasts of high accessibility, low cost, and short waiting times, and it is easy to collect data for planning, researching, monitoring, and evaluating the various medical services. All hospitals and clinics in Korea must provide the HIRA with information on the diagnosis, treatment, and clinical behavior, etc. of outpatients and in patients in order to invoice it for costs. Therefore, in addition to personal information such as age and gender of patients, all information on diagnoses, examinations performed, and treatment can be acquired through the data of the HIRA. When the HIRA provides such information, however, all of it including personal identities is encrypted in order to protect the personal information and data of patients. There has recently been a surge in epidemiological research using HIRA's data [18].

The participants for this study were acute SCI patients registered in the HIRA data between January 1, 2007 and December 31, 2017. The patients were identified using the International Classification of Disease (ICD-10) codes (Table 1), and 12,137 patients categorized in this way were classified according to gender and 10-year age groups.

\section{Assessment of high dose methylprednisolone prescription and related complication rate}

Patients that received high dose methylprednisolone (National Acute Spinal Cord Injury Study (NASCIS) 3 protocol: methylprednisolone $30 \mathrm{mg} / \mathrm{kg}$ bolus over $15 \mathrm{~min}$, followed by $45 \mathrm{~min}$ of rest period, then $5.4 \mathrm{mg} / \mathrm{kg} / \mathrm{h}$ for $23 \mathrm{~h}$ if they were within $3 \mathrm{~h}$ of injury. If treatment started between 3 and $8 \mathrm{~h}$ after injury, methylprednisolone $30 \mathrm{mg} / \mathrm{kg}$ bolus over $15 \mathrm{~min}$, followed by $45 \mathrm{~min}$ of rest period, then $5.4 \mathrm{mg} / \mathrm{kg} / \mathrm{h}$ for $48 \mathrm{~h}$ ) were identified by the medical behavior code (193604BIJ) for prescriptions to acute SCI patients categorized by the ICD-10 code. In order to exclude uses of methylprednisolone to treat other diseases, patients who attended outpatient clinics and received low dose methylprednisolone were excluded. Annual prescription rate of high dose methylprednisolone was investigated to assess its trend. Patients were divided into an MP group and a non-MP group for analyses of pneumonia, urinary tract infections, gastrointestinal tract hemorrhage, and wound infections in order to investigate the complication rate following high dose methylprednisolone treatment.
Table 1 ICD-10 codes for searching cohorts

\begin{tabular}{lll}
\hline Parameters & Codes & Description \\
\hline ICD-10 code & S14 & Injury of nerves and spinal cord at neck level \\
& S14.0 & Concussion and edema of cervical spinal cord \\
S14.1 & Other and unspecified injuries of cervical spinal cord \\
S24 & Injury of nerves and spinal cord at thorax level \\
S24.0 & Concussion and edema of thoracic spinal cord \\
S24.1 & Other and unspecified injuries of thoracic spinal cord \\
S34 & Injury of lumbar and sacral spinal cord and nerves at abdomen, lower back and \\
& pelvis level \\
& S34.0 & Concussion and edema of lumbar and sacral spinal cord \\
S34.1 & Other and unspecified injury of lumbar and sacral spinal cord \\
\hline
\end{tabular}


Table 2 ICD-10 codes for searching cohorts

\begin{tabular}{lll}
\hline Parameters & Description & Codes \\
\hline ICD-10 code & Pneumonia & $\mathrm{J} 12^{\mathrm{a}}, \mathrm{J} 13, \mathrm{~J} 14, \mathrm{~J} 15^{\mathrm{a}}, \mathrm{J} 16^{\mathrm{a}}$, \\
& & $\mathrm{J} 17^{\mathrm{a}}, \mathrm{J} 18^{\mathrm{a}}$ \\
& Gastrointestinal bleeding & $\mathrm{K} 25^{\mathrm{a}}, \mathrm{K} 26^{\mathrm{a}}, \mathrm{K} 27^{\mathrm{a}}, \mathrm{K} 28^{\mathrm{a}}$, \\
& $\mathrm{K} 29, \mathrm{~K} 92^{\mathrm{a}}$ \\
& Urinary tract infection & $\mathrm{N} 30^{\mathrm{a}}, \mathrm{N} 34^{\mathrm{a}}, \mathrm{N} 41^{\mathrm{a}}$ \\
& Wound infection & $\mathrm{M} 46^{\mathrm{a}}, \mathrm{T} 81^{\mathrm{a}}$
\end{tabular}

${ }^{\mathrm{a}}$ Means that all sub-codes of the respective code are included

Complications were defined when pneumonia, urinary tract infection, gastrointestinal tract hemorrhage or wound infection occurred within three months of MP administration. In order to assess whether complications occurred due to the use of methylprednisolone, patients were categorized using the ICD-10 codes related to each complication (Table 2).

\section{Statistical analysis}

SPSS 21.0 (SPPS Inc., Chicago, IL, USA) was used for statistical analysis. Student's $t$-test was used for continuous variables, and the chi square test was used to analyze classification variables. The Joinpoint Regression Program version 4.3.1.0 (National Cancer Institute, Bethesda, MD, USA) was also used. Age-adjusted incidences were calculated employing the standard population of the Republic of Korea according to age and gender registered on the Korean Statistical Information Service website (http://www.kosis.kr) and the 2000 US Standard Population (https://seer.cancer. gov), and annual percentage changes were calculated. Odds ratio and $95 \%$ confidence interval of each complications were calculated. Statistically significance was defined as $P<0.05$.

\section{Results}

A total of $12,137(\mathrm{M}: \mathrm{F}=3.4: 1)$ patients were identified with acute SCI over 11 years from 2007 to 2017. The ageadjusted average incidence of acute SCI was $26.4 \pm 0.9$ persons per million persons (Table 3 ). The annual percentage change for age-adjusted average incidence has increased by $2 \%$ for men and $2 \%$ for women $(p<0.001$ respectively). However, while the overall trend towards an increase was $1 \%$, it was not statistically significant ( $p=$ 0.2 ). The mean age for men was $59.5 \pm 14.4$ years (range 6-94 years) and for women $54.9 \pm 15.4$ years (range 4-95 years), and the incidence was highest in men in their $50 \mathrm{~s}$ and in women in their $70 \mathrm{~s}$. Overall, the highest incidence occurred in individuals in their $50 \mathrm{~s}$ (Fig. 1).

Methylprednisolone was prescribed to $59 \%$ of all acute SCI patients over the past 11 years. The prescription rate
Table 3 Number of cases, and age-adjusted rates of spinal cord injury, from 2007 to 2017

\begin{tabular}{|c|c|c|c|c|c|c|}
\hline \multirow[t]{2}{*}{ Year } & \multicolumn{3}{|c|}{ No. of cases } & \multicolumn{3}{|c|}{$\begin{array}{l}\text { Age-adjusted rate per } \\
100,000 \text { persons }\end{array}$} \\
\hline & Total & Men & Women & Total & Men & Women \\
\hline 2007 & 1156 & 856 & 300 & 25.07 & 36.48 & 11.31 \\
\hline 2008 & 905 & 654 & 251 & 25.33 & 37.2 & 11.54 \\
\hline 2009 & 967 & 718 & 249 & 25.6 & 37.92 & 11.77 \\
\hline 2010 & 1101 & 776 & 325 & 25.86 & 38.67 & 12.01 \\
\hline 2011 & 1061 & 795 & 266 & 26.13 & 39.42 & 12.25 \\
\hline 2012 & 1004 & 742 & 262 & 26.4 & 40.2 & 12.49 \\
\hline 2013 & 1104 & 810 & 294 & 26.68 & 40.98 & 12.74 \\
\hline 2014 & 1231 & 848 & 383 & 26.95 & 41.78 & 13 \\
\hline 2015 & 1164 & 872 & 292 & 27.23 & 42.6 & 13.26 \\
\hline 2016 & 1285 & 940 & 345 & 27.52 & 43.44 & 13.53 \\
\hline 2017 & 1159 & 852 & 307 & 27.8 & 44.29 & 13.8 \\
\hline Overall & 12137 & 8863. & 3274 & 26.4 & 40.3 & 12.5 \\
\hline APC & & 1.0 & 2.0 & 2.0 & & \\
\hline
\end{tabular}

$A P C$ annual percentage change

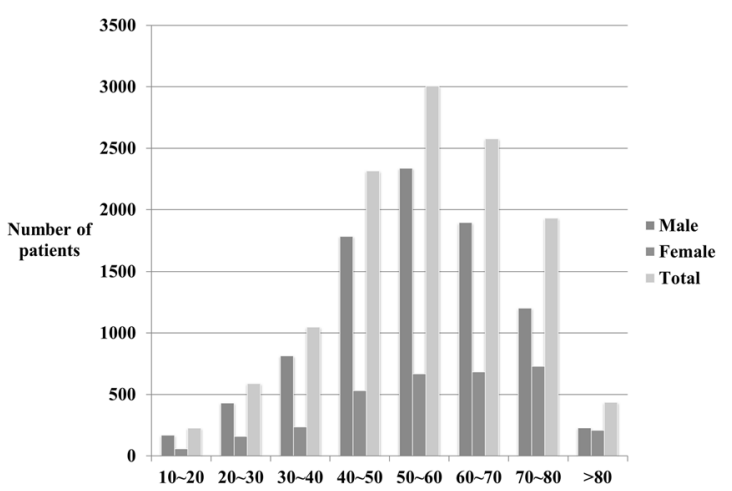

Fig. 1 Numbers of spinal cord injury patients over 11 years according to age

was highest in 2012 at $76 \%$ and decreased gradually to a low of $41 \%$ in 2017 (Table 4) (Fig. 2). Compared with the non-MP group, the MP group had increased risks of pneumonia (OR 1.8, 95\% CI, 1.62-2.0), gastrointestinal tract hemorrhage (OR 1.2, 95\% CI, 1.05-1.38) and urinary tract infections (OR 1.68, 95\% CI, 1.53-1.84). The risk of wound infection (OR 0.98, 95\% CI, 0.77-1.25) did not differ between the two groups (Fig. 3). The mean hospitalization period was $26.5 \pm 19.2$ days for the MP group, and $24.4 \pm 16.5$ for the non-MP group $(p=0.002)$.

\section{Discussion}

The incidence of acute SCI per million persons was reported as 39 in North America, 15 in Australia, and 16 in 
Table 4 Methylprednisolone treatment of acute spinal cord injury patients

\begin{tabular}{llll}
\hline Year & $\begin{array}{l}\text { Number of } \\
\text { cases of } \\
\text { acute spinal } \\
\text { cord injury }\end{array}$ & $\begin{array}{l}\text { No. of cases } \\
\text { receiving } \\
\text { methylprednisolone }\end{array}$ & $\begin{array}{l}\text { Prescription } \\
\text { rate }(\%)\end{array}$ \\
\hline 2007 & 1156 & 789 & 68.3 \\
2008 & 905 & 600 & 66.3 \\
2009 & 967 & 619 & 64.0 \\
2010 & 1101 & 750 & 68.1 \\
2011 & 1061 & 726 & 68.4 \\
2012 & 1004 & 760 & 75.7 \\
2013 & 1104 & 719 & 65.1 \\
2014 & 1231 & 702 & 57.0 \\
2015 & 1164 & 658 & 56.5 \\
2016 & 1285 & 598 & 46.5 \\
2017 & 1159 & 472 & 40.7 \\
Total & 12,137 & 7183 & 61.5 \\
\hline
\end{tabular}

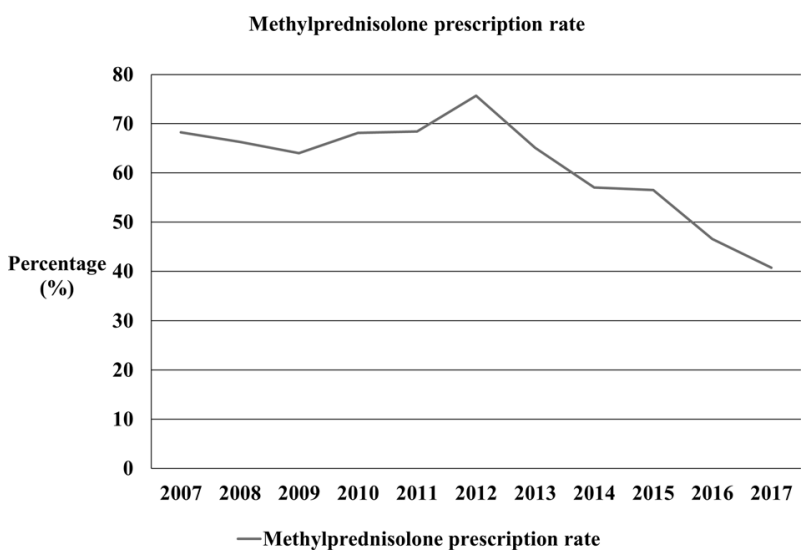

Fig. 2 High dose methylprednisolone prescription rate over the years

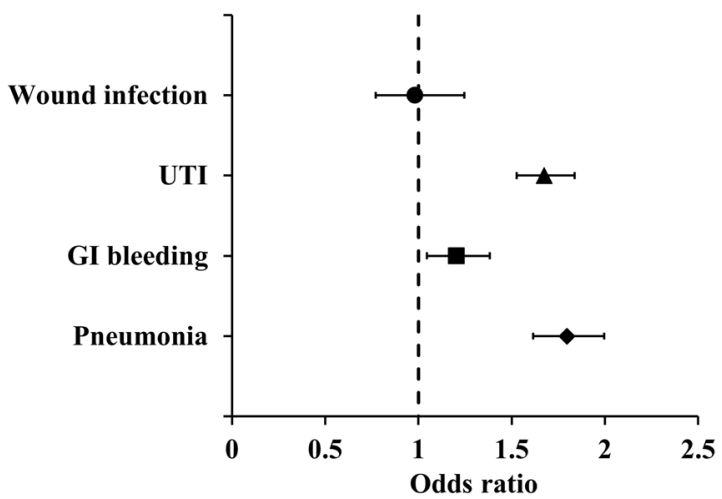

Fig. 3 The risk of complications in the methylprednisolone group compared with non-methylprednisolone group
Western Europe [3], while in Asia, it was reported as 40.2 in Japan [19], and 18.8 in Taiwan [20]. However, studies on the epidemiology of acute SCI per country or region have focused mainly on developed countries. There have been a few reports comparing the worldwide prevalence and incidence of acute SCI, but because there have been no studies of the epidemiology of acute SCI in many developing countries including South Korea it is difficult to assess global epidemiology [3, 4, 11]. In most studies, male patients accounted for the majority and incidence was highest in those under 30. In this study, the age-adjusted average incidence per million persons was 26.4, and the male-to-female ratio was 3.41:1. This incidence and maleto-female ratio were similar to those of other developed nations. However, the age of peak incidence in South Korea was highest in the $50 \mathrm{~s}$ which was older than in other countries. This may have been associated with the fact that there is a higher incidence of ossified posterior longitudinal ligament (OPLL) in the older age groups of South Korea, as well as that the degenerative spondyloses in the rapidly aging South Korean society escalates the risk of posttraumatic acute SCI. Between 2002 and 2013, annual incidence of OPLL was 199-371 per million persons in South Korea and the peak age of annual incidence was 60-75 years [21]. The incidence of acute SCI in Japan was also highest in people in their $50 \mathrm{~s}$ [19] and it has been reported that Japan's OPLL incidence is also higher than in other countries [22]. Therefore, as the population of Korea is aging, there is an increasing possibility of acute SCI in older patients, and this should be reflected in planning out how to prevent acute SCI and how to allocate medical resources.

The apparent incidence of acute SCI differs by region, and even in the same region, it can vary with the study period [11]. While this may be the result of demographical or geographical characteristics, it may also be due to the use of different research modalities. For example, hospitalbased studies tend to undervalue specific disease incidences compared with population-based studies [23]. Therefore, in order to make international comparisons or to accurately estimate global incidence, the data collection method needs to be standardized.

High dose methylprednisolone has been recommended for use as it is the only drug with proven effectiveness on neural protection for acute SCI patients based on the results of the NASCIS [24]. However, many studies have questioned the quality of the data of the NASCIS research, its statistical analysis method, interpretation, and conclusions. Furthermore, there is no Class I or Class II evidence for the beneficial effect of methylprednisolone, and the FDA no longer recommends its use for treating acute SCI [15, 16]. Despite this, many clinicians still prescribe methylprednisolone. According to one study, some clinicians believe that it is effective for acute SCI, while others know that it is 
ineffective, but think that they have to do something for the patient; some clinicians prescribe it to avoid medical litigation for not using the drug [17].

Worldwide, methylprednisolone is prescribed in $53 \%$ of cases, and in Canada, its use dropped from 76\% in 2001 to $24 \%$ in 2006, and in England, from $68 \%$ in 2004 to $19 \%$ in $2012[25,26]$, apparently as the effect of studies on the side effects and inefficacy of methylprednisolone [24, 27]. In this study, South Korea had the highest prescription rate in $2012(76 \%)$ and then declined to $41 \%$ in 2017 . However, South Korea still has a high prescription rate compared with North America and Europe, and education and notification is needed especially for spine surgeons to ensure that they do not use methylprednisolone inappropriately.

Early studies reported that treatment of acute SCI patients with methylprednisolone increased the risk of complications such as pneumonia, gastrointestinal hemorrhage, urinary tract infection, wound infection, hyperglycemia, myopathy, and sepsis [28-30]. In this study we found that when compared with the non-MP group, the MP group showed a higher correlation with pneumonia, gastrointestinal hemorrhage and urinary tract infections, but there was no difference between the two groups in terms of wound infection. According to research by Suberviola et al. [30], the incidence of pneumonia was significantly higher in the methylprednisolone user group, but again no substantial difference in wound infections. Matsumoto et al. [29] reported a higher incidence of pneumonia and gastrointestinal hemorrhage in the group using methylprednisolone, but no difference in urinary tract infection incidence. However, Ito et al. [28] reported an increased incidence of pneumonia, urinary tract infections, and wound infections. The differences among these studies may have been due to variation in the severity and extent of neurologic deficits as well as in the definitions of complications. It is likely that our MP group had a longer hospitalization period than the non-MP group due to the difference in complication rates (26.5 vs. 24.4).

This is the first study of the incidence of acute SCI in South Korea using a population-based database, and it is significant in that it analyzed the methylprednisolone prescription rate and the incidence of complications based on a large sample size. However, it has a few limitations. First, it is a retrospective study. Second, the HIRA database is constructed for the purpose of invoicing, and data may have been omitted or entered erroneously in the event that South Korean hospitals or clinics failed to enter the correct ICD-10 codes or medical practice codes during examinations and treatments. This might affect the overall results on the incidence of acute SCI and the occurrence of complications. But it was a large population-based study, we believe such errors had little effect on our results. Third, only four complications which were known to be common complication of high dose methylprednisolone therapy were evaluated. There usually were other complications such as decubital wounds and deep vein thrombosis, but we focused on major complications [28-30]. Fourth, because we just used a simple comparison of those that did and did not receive methylprednisolone to assess complications, it is difficult to suggest a causation. However, this study could show some correlation between two variables by analyzing large size sample. Fifth, because it is not possible to conduct surveys on whether methylprednisolone improves neurological symptoms in acute SCI patients, only the use of methylprednisolone and the resulting complications were investigated.

This is the first epidemiological study of acute SCI in South Korea. Its average incidence in the past 11 years was 26.4 per 1 million persons, and peak incidence occurred in the $50 \mathrm{~s}$ age group. This should be reflected in policies for preventing the occurrence of acute SCI and distributing medical resources. Despite the doubts over the efficacy of methylprednisolone treatment and the known complications, it is still frequently prescribed for acute $\mathrm{SCI}$ in Korea.

\section{Data archiving}

All data generated or analyzed during this study are included in this published article and its supplementary material file. They are also available from the HIRA website (https://www.hira.or.kr) on reasonable request.

Author contributions SHC and CNK were responsible for designing the cohort study. CS was responsible for preparing the manuscript content. DRH and SYJ contributed on revising the manuscript content.

Funding No financial assistance was received in support of the study.

\section{Compliance with ethical standards}

Conflict of interest The authors declare that they have no conflict of interest.

Ethics statement This study was approved according to the standards of the Hanyang University Hospital institutional review board (HYUH 2018-06-037).

Publisher's note Springer Nature remains neutral with regard to jurisdictional claims in published maps and institutional affiliations.

\section{References}

1. McCammon JR, Ethans K. Spinal cord injury in Manitoba: a provincial epidemiological study. J Spinal Cord Med. 2011; 34:6-10.

2. Pickett W, Simpson K, Walker J, Brison RJ. Traumatic spinal cord injury in Ontario, Canada. J Trauma. 2003;55:1070-6.

3. Cripps RA, Lee BB, Wing P, Weerts E, Mackay J, Brown D. A global map for traumatic spinal cord injury epidemiology: towards a living data repository for injury prevention. Spinal Cord. 2011;49:493-501. 
4. Wyndaele M, Wyndaele JJ. Incidence, prevalence and epidemiology of spinal cord injury: what learns a worldwide literature survey? Spinal Cord. 2006;44:523-9.

5. Burney RE, Maio RF, Maynard F, Karunas R. Incidence, characteristics, and outcome of spinal cord injury at trauma centers in North America. Arch Surg. 1993;128:596-9.

6. DeVivo MJ, Vogel LC. Epidemiology of spinal cord injury in children and adolescents. J Spinal Cord Med. 2004;27(Suppl 1): S4-10.

7. Lofvenmark I, Norrbrink C, Nilsson-Wikmar L, Hultling C, Chakandinakira S, Hasselberg M. Traumatic spinal cord injury in Botswana: characteristics, aetiology and mortality. Spinal Cord. 2015;53:150-4.

8. Sabre L, Remmer S, Adams A, Vali M, Rekand T, Asser T, et al. Impact of fatal cases on the epidemiology of traumatic spinal cord injury in Estonia. Eur J Neurol. 2015;22:768-72.

9. Bracken MB. Steroids for acute spinal cord injury. Cochrane Database Syst Rev. 2012;1:Cd001046.

10. Nobunaga AI, Go BK, Karunas RB. Recent demographic and injury trends in people served by the model spinal cord injury care systems. Arch Phys Med Rehabil. 1999;80:1372-82.

11. Singh A, Tetreault L, Kalsi-Ryan S, Nouri A, Fehlings MG. Global prevalence and incidence of traumatic spinal cord injury. Clin Epidemiol. 2014;6:309-31.

12. Bracken MB, Shepard MJ, Collins WF, Holford TR, Young W, Baskin DS, et al. A randomized, controlled trial of methylprednisolone or naloxone in the treatment of acute spinal-cord injury. Results of the second national acute spinal cord injury study. N Engl J Med. 1990;322:1405-11.

13. Braakman R, Schouten HJ. Blaauw-van Dishoeck M, Minderhoud JM. Megadose steroids in severe head injury. Results of a prospective double-blind clinical trial. J Neurosurg. 1983; 58:326-30.

14. Bydon M, Lin J, Macki M, Gokaslan ZL, Bydon A. The current role of steroids in acute spinal cord injury. World Neurosurg. 2014;82:848-54.

15. Hurlbert RJ, Hadley MN, Walters BC, Aarabi B, Dhall SS, Gelb DE, et al. Pharmacological therapy for acute spinal cord injury. Neurosurgery. 2013;72:93-105.

16. Walters BC, Hadley MN, Hurlbert RJ, Aarabi B, Dhall SS, Gelb $\mathrm{DE}$, et al. Guidelines for the management of acute cervical spine and spinal cord injuries: 2013 update. Neurosurgery. 2013;60 (Suppl 1):82-91.

17. Falavigna A, Quadros FW, Teles AR, Wong CC, Barbagallo G, Brodke D, et al. Worldwide steroid prescription for acute spinal cord injury. Glob Spine J. 2018;8:303-10.
18. Kim JA, Yoon SJ, Kim LY, Kim DS. Towards actualizing the value potential of Korea health insurance review and assessment (HIRA) data as a resource for health research: strenths, limitations, applications, and strategies for optimal use of HIRA data. J Korean Med Sci. 2018;32:718-28.

19. Shingu H, Ohama M, Ikata T, Katoh S, Akatsu T. A nationwide epidemiological survey of spinal cord injuries in Japan from January 1990 to December 1992. Paraplegia. 1995;33:183-8.

20. Chen CF, Lien IN. Spinal cord injuries in Taipei, Taiwan, 1978-81. Paraplegia. 1985;23:364-70.

21. Moon BJ, Choi SK, Shin DA, Yi S, Kim KN, Yoon DH, et al. Prevalence, incidence, comorbidity, and mortality rates of ossification of posterior longitudinal ligament in the cervical spine: a nested case-control cohort study. World Neurosurg. 2018;117:e323-e328.

22. Sasaki E, Ono A, Yokoyama T, Wada K, Tanaka T, Kumagai G, et al. Prevalence and symptom of ossification of posterior longitudinal ligaments in the Japanese general population. J Orthop Sci. 2014;19:405-11.

23. Rahimi-Movaghar V, Saadat S, Rasouli MR, Ganji S, Ghahramani M, Zarei MR, et al. Prevalence of spinal cord injury in Tehran, Iran. J Spinal Cord Med. 2009;32:428-31.

24. Bracken MB, Holford TR. Effects of timing of methylprednisolone or naloxone administration on recovery of segmental and long-tract neurological function in NASCIS 2. J Neurosurg. 1993;79:500-7.

25. Hurlbert RJ, Hamilton MG. Methylprednisolone for acute spinal cord injury: 5-year practice reversal. Can J Neurol Sci. 2008; $35: 41-45$.

26. Werndle MC, Zoumprouli A, Sedgwick P, Papadopoulos MC. Variability in the treatment of acute spinal cord injury in the United Kingdom: results of a national survey. J Neurotrauma. 2012;29:880-8.

27. Gerndt SJ, Rodriguez JL, Pawlik JW, Taheri PA, Wahl WL, Micheals AJ, et al. Consequences of high-dose steroid therapy for acute spinal cord injury. J Trauma. 1997;42:279-84.

28. Ito Y, Sugimoto Y, Tomioka M, Kai N, Tanaka M. Does high dose methylprednisolone sodium succinate really improve neurological status in patient with acute cervical cord injury? A prospective study about neurological recovery and early complications. Spine. 2009;34:2121-4.

29. Matsumoto T, Tamaki T, Kawakami M, Yoshida M, Ando M, Yamada H. Early complications of high-dose methylprednisolone sodium succinate treatment in the follow-up of acute cervical spinal cord injury. Spine. 2001;26:426-30.

30. Suberviola B, Gonzalez-Castro A, Llorca J, Ortiz-Melon F, Minambres E. Early complications of high-dose methylprednisolone in acute spinal cord injury patients. Injury. 2008;39:748-52. 